\title{
2. Povoamento rural na Lusitania
}

\author{
André Carneiro \\ Universidade de Évora \\ ORCID: 0000-0002-0824-3301 \\ ampc@uevora.pt
}

\begin{abstract}
Sumário: A presença romana no território português constituiu uma profunda viragem nos modos de se viver e trabalhar o campo. Para além das práticas agro-pecuárias que se intensificam, o mundo rural é entendido como um espaço de refúgio e desfrute das elites urbanas, o que levou a investimentos que criaram residências providas de arquiteturas e decorações sumptuosas.
\end{abstract}

\section{Os conceitos: Roma e o mundo rural, entre a res urbana e a res rustica}

Nas mais recentes décadas, poucas áreas de conhecimento evoluíram tanto como o estudo do povoamento rural romano. Para além das recentes descobertas arqueológicas, temos uma distinta leitura dos textos e da vivência da época, que nos permitem novas perspetivas desta realidade. Mas, sobretudo, construiu-se uma intensidade de pesquisa radicalmente distinta, graças à denominada "Arqueologia de território" e/ou de empresa, que nos mostrou como as paisagens romanas foram complexas e multifacetadas a um grau dificilmente imaginável nos finais do milénio anterior.

Em época clássica, campo e cidade são elementos próximos, indissociáveis e complementares, e esta sinergia constitui uma estrutura radicalmente nova para o território português, visto que no mundo indígena pré-romano não existe um padrão de povoamento rural conectado com núcleos urbanos. O campo alimenta a cidade, e esta abastece o campo; mas além da relação meramente utilitária, nos seus códigos éticos, a mentalidade romana considera os valores associados à vivência campestre como estruturantes para o progresso individual, pois o esforço, o despojamento e a perseverança que a agricultura exige são paradigmas transversais no plano cultural latino-itálico. Sendo uma 
civilização da Cidade (Urbs Romana) e de cidades, Roma mantém com o campo uma proximidade constante e que se amplia após a conquista dos territórios helénicos, momento no qual a vivência rural passa também a ser encarada como um local de refúgio, convívio e de otium, ou seja, onde o cidadão reforçava os seus laços clientelares recebendo os amigos e convivas, propiciando também um espaço para a leitura e reflexão pessoal. Por estes motivos a residência no campo (villa) torna-se um edifício semi-público progressivamente mais confortável, ostentatório e luxuoso, provido de todos os requintes de uma casa urbana (domus). O campo abastecia a cidade, mas daqui partia a elite buscando os momentos de tranquilidade que só o mundo rural proporcionava, havendo uma inter-relação tão próxima que cidade e campo estavam inseridos no mesmo desenho de planeamento territorial feito pelos agrimensores. Compreendem-se assim as recomendaçóes contidas nos textos sobre a proximidade e a facilidade de acesso que deveriam existir entre estes dois mundos ${ }^{1}$, ou o modo natural como as mesmas pessoas por eles transitavam.

Este paradigma explica que o investimento na posse da terra fosse desejável e incentivado. Quem não detinha terras estava afastado dos direitos civis e políticos, e até ao governo de Mário estava impedido de servir nas legiōes. O protótipo vivencial do cidadão latino, portanto, baseava-se em deter património fundiário, sendo desaconselháveis as propriedades demasiado extensas, cuja gestão poderia ser menos eficaz. Era preferível deter vários domínios, mesmo que em pontos distantes (incluindo em diferentes províncias), do que enormes extensões contínuas. Na época seriam pouco frequentes os latifúndios, ao contrário do presumido na investigação, devido à transposição acrítica da paisagem etnográfico-económica dominante na atualidade (em especial na região alentejana, onde os vestígios romanos estão mais bem conservados) para o momento histórico em causa. Este costume mostra também que não existe uma relação direta entre os ganhos obtidos na exploração da propriedade e o investimento feito nas suas estruturas e elementos arquitetónicos, visto que o proprietário poderia ter outras fontes de rendimento ou, inversamente, direcionar os seus proveitos para outras propriedades ou negócios. Por fim, note-se que, apesar do retrato idílico que os textos nos deixaram da vivência campestre, era na cidade que os jogos de poder e a visibilidade político-social se processavam, pelo que o ideal rural foi mais um paradigma do que uma vivência efetiva.

De forma paradoxal, contudo, tem sido sempre a componente urbana do campo a atrair o olhar dos investigadores, fascinados com a riqueza material e decorativa do seu maior emblema: a villa, residência campestre que espelha o poder e influência do proprietário. Trata-se do elemento que materializa e concilia esta junção de opostos que a civilização romana idealizou: entre a rusticitas do campo e a voluptas da riqueza decorativa, cria-se um espaço arquitetónico de residência ao gosto urbano, com áreas de conforto como termas, jardins e salas de

${ }^{1}$ Plínio-o-Jovem, Ep. 2.17.2. 
banquete (a designada pars urbana). A propriedade abarcava também, em geral, um conjunto de lagares, adegas, celeiros ${ }^{2}$, armazéns, estábulos e outros espaços consagrados às atividades agro-pecuárias (pars rustica ou fructuaria) ou económicas, como fornos, forjas ou oficinas de tecelagem. Sabemos ainda que estruturas autónomas como templos e escritórios ou espaços de leitura poderiam encontrar-se no fundus (o domínio da exploração), configurando construções arquitetónicas próprias e isoladas, para além de poderem existir estruturas semi-públicas, ou seja, acessíveis aos habitantes das redondezas ou a viajantes. Portanto, a villa era um espaço multifuncional, dotado de múltiplas valências, e personalizado ao extremo, na medida em que expressava as ambiçōes e interesses do(s) seu(s) proprietário(s). Emblema por excelência da sociedade que a criou, a villa tem polarizado a investigação arqueológica, pela riqueza decorativa e de conteúdos culturais. Desta forma, quando olhamos para a paisagem rural, é a villa que sobressai, estando os restantes componentes do tecido de povoamento ainda mal conhecidos.

A villa encontra-se numericamente bem representada em todo o atual território português, embora seja evidente uma concentração no sudoeste peninsular, na área que em traços gerais corresponde ao Alentejo central ${ }^{3}$. Esta maior densidade ocorre, não apenas pela intensidade da investigação arqueológica (facilitada pela repartição da propriedade em latifúndios), mas também por ser a região que mais se aproxima das paisagens ideais que os romanos tinham como referente. A repartição é, no entanto, desigual, ocorrendo com enorme intensidade em torno a algumas urbes, em especial na envolvente de Pax Iulia (Beja) e de Ebora Liberalitas Iulia (Évora), e espaçando-se em paisagens mais distantes do ideal mediterrânico, como as serranias do litoral, as terras de areias da bacia do Tejo ou os ondulados xistosos das serras algarvias. A norte do Tejo, em contrapartida, a investigação arqueológica recente ${ }^{4}$ tem comprovado uma ocupação do território rural que, por vezes, apresenta densidades surpreendentes, embora também com apreciáveis desigualdades consoante o tipo de paisagem, a facilidade de acessos e a proximidade a alguma urbs.

\section{Os produtos e produçôes: frutos da terra e economia rural}

$\mathrm{Na}$ investigação sobre a paisagem rural romana existe um paradigma consensual: a omnipresença da agricultura de sequeiro, consubstanciada na tríade mediterrânica, ou no privilegiar da exploração baseada nos cereais, no vinho e no azeite. Trata-se de uma visão empobrecedora, como uma simples visão cartográfica da dispersão de barragens, tanques e outras estruturas de contenção

${ }^{2}$ Destacando-se o de Freiria (Cascais), que pelas suas dimensões é o maior identificado na Península.

${ }^{3}$ Lopes 2003; Carneiro 2014.

${ }^{4}$ Ver, por exemplo, Carvalho 2007; Bernardes 2007. 
de água ${ }^{5}$ pode avaliar, mostrando-nos que há muito a fazer na valorização da agricultura de regadio em época romana, uma atividade ainda desconhecida na Lusitania. Pela informação arqueológica em outras províncias e textos da época, sabemos que a base de sustento das villae era mais ampla e especializada do que a geralmente suposta: desde a produção de reputados perfumes e flores a objetos de artesanato em matérias-primas variadas, da piscicultura ao aproveitamento de filóes mineiros ou de pedras de cantaria, o panorama foi variado, propiciando que algumas villae tivessem pequenos territórios de exploração, ou não dispusessem de pars rustica, ou seja, das infra-estruturas de vocação produtiva. Esta situação pode ser suportada pelas menções literárias à excelência dos tecidos produzidos (e possivelmente também tintados) no atual território português, como no caso das lãs de Salacia e dos linhos da região dos Zoelas, elementos económicos importantes em época imperial ${ }^{6}$, no quadro da exportação para outras regiōes do Império.

Todavia, por falta de investigação direcionada para estes casos concretos, é ainda o panorama tradicional que predomina, facilitado por esta ser a paisagem característica do campo português: as searas, as vinhas e os olivais levam a que se transponha para o mundo rural romano o modelo económico vigente. E em boa verdade, os casos que fogem a esta realidade são ainda a exceção: em Casais Velhos (Cascais) os tanques advogam um estabelecimento com amplas oficinas de tinturarias de tecidos, ou em Nogueiras (Borba) poderíamos ter a exploração de mármores. Em Magra (Beja) foi recentemente identificada uma exploração de fornos de cal, enquanto que várias villae do litoral do Algarve teriam produções de preparados de peixe associadas a oficinas de produção de contentores cerâmicos (figlinae). Mas estes são casos minoritários: seja por falta de investigação direcionada ou pela realidade da época, são os pontos onde se produziram vinho e azeite os que dominam a cartografia, por vezes de modo impressivo, seja pela frequência de pesos de lagar (como na área de Serpa) ou pelas dimensões do espaço de lagar, como em Milreu (Faro), que evidencia uma escala para exportação. Tal pode ser comprovado a partir da dispersão de prensas e elementos de lagar ${ }^{7}$, com uma interessante coincidência entre as áreas de concentração de complexos de produção vitivinícola/oleícola com as áreas atuais, embora também se registem curiosas ausências ${ }^{8}$. Esta agricultura de sequeiro com base extensiva era menos exigente na angariação e preparação de mão-de-obra, o que ajudou a manter baixos custos de exploração. Desta forma, a produção de cereais, azeite e vinho dominou a base económica rural da Lusitania embora, como foi referido,

${ }^{5}$ Quintela, Cardoso e Mascarenhas 1987.

${ }^{6}$ Plínio-o-Velho, Nat. Hist. 8,191 e 19,10.

${ }^{7}$ Consulte-se o extenso inventário realizado por Yolanda Peña Cervantes (2010).

${ }^{8}$ Por exemplo, o eixo de Estremoz e Borba, região de afamados vinhos e azeites, onde em época romana apenas os sítios de Santa Vitória do Ameixial e de Herdade da Coelha apresentam evidências de produção, no caso, de torcularium de azeite. 
existam interessantes nichos de mercado a explorar, que uma investigação aprofundada certamente virá a revelar.

\section{As pessoas: do desfrute do otium rural às forças vivas de trabalho}

Os dados de cariz paleo-económico são escassos, mas não custa supor a grande diversidade nos regimes de exploração da terra, quer na extensão da propriedade, quer nas produções obtidas. Infelizmente, vários elementos de análise nos faltam quase por completo: a epigrafia e o mundo funerário. No primeiro caso, raros são os elementos cuja onomástica pode ser inequivocamente atribuída a uma exploração: o célebre caso de villa Cardilius (Torres Novas), onde um mosaico regista uma inscrição com nome e representação figurativa dos prováveis proprietários ${ }^{9}$, ou Torre de Palma (Monforte), onde Marcus Coelius Celsus dedicou uma ara a Marte enquanto divindade benfazeja da agricultura ${ }^{10}$, são exemplos raros. Embora indireto, outro dado interessante assoma em inscrição desta área regional: a epígrafe de Ervedal ${ }^{11}$ (Avis) que menciona Threptus, auto-denominado servus de Caius Appuleius Silo, ou seja, o seu villicus ou capataz da exploração (sendo que o nome denuncia a sua condição de escravo) encarregue de a gerir em nome de um proprietário absentista.

Quanto aos dados provenientes do universo funerário, alguns mausoléus foram identificados ${ }^{12}$, alguns elementos arquitetónicos descontextualizados denunciam a sua presença ${ }^{13}$, e em outros casos temos placas monumentais que deixam antever a sua existência ${ }^{14}$, mas os dados continuam a ser lacunares. Veja-se, por exemplo, que raros são os estabelecimentos rurais com necrópole identificada, e menos ainda são os casos em que ambos os espaços foram simultaneamente escavados. Na região de Elvas, a década de 50 do século XX

${ }^{9}$ VIVENTES CARDILIVM ET AVITAM FELIX TVRRE, inscrição aposta como legenda dos dois bustos, que surgem separados por uma foice, um interessante indicador de cariz produtivo.

${ }^{10}$ Encarnação 1984: no 568. Note-se que pode existir uma relação entre este dedicante e $Q$. Coelius Cassianus, duúnviro olisiponense relacionado com as termas dos Cássios e que também tinha propriedades na área de Dois Portos (Torres Vedras).

${ }^{11}$ Encarnação 1984: no 437.

${ }^{12} \mathrm{O}$ mais bem conservado será o de Quinta da Romeira de Baixo (Loures), mas destaquem-se os casos de Pisões (Beja), Cerro da Vila (Vilamoura), Milreu (Faro) ou Torre de Palma (Monforte). A frequência de mausoléus deveria ser maior do que geralmente julgado, em especial no Algarve ou em torno a Olisipo, dada a existência de epígrafes funerárias de caráter monumental.

${ }^{13}$ Veja-se o pulvinum, um componente decorativo da terminação de um mausoléu em forma de altar, proveniente de Quinta da Fórnea (Belmonte), como único exemplo provincial em meio rural: Santos, Carvalho 2008.

${ }^{14}$ Por exemplo, a de São Pedro de Almuro, da família Preccia (Monforte, Encarnação 1984: nº 595a). Merece destaque o epitáfio de N. Sr. ${ }^{a}$ da Tourega (Évora, idem no 382), por testemunhar duas famílias (Iulia e Calpurnia) de relevantes cargos públicos em outras províncias do Império. 
assistiu a intervenções arqueológicas de emergência em necrópoles rurais, promovidas por Abel Viana e António Dias de Deus, mas que não foram suficientemente correlacionadas com as villae nas imediações. Todavia, a principal impressão que fica é a de que as necrópoles escavadas, pela sua extensão e relativa monotonia de espólio, poderão corresponder a trabalhadores livres que prestassem serviço nas villae envolventes, e não tanto aos sepulcros dos donos dos estabelecimentos. Tendo este panorama presente, não custa assumir que, apesar dos progressos da investigação, detemos um curioso paradoxo: conhecemos melhor os espaços de vida das elites do que os sítios modestos - individuais (casais agrícolas) ou coletivos (aldeias e povoados) - onde viviam os trabalhadores, mas no mundo funerário é precisamente o panorama inverso que temos, ou seja, os sepulcros identificados são algo pobres e monocórdicos, deixando perceber que as derradeiras moradas dos domini não foram, salvo raras exceções, identificadas.

Eram precisamente estes grandes senhores da terra que levavam a cabo, nas suas residências de campo, uma vida que era, também, paradoxal e contrastante. A villa era o local de retiro do bulício da cidade, para onde sazonalmente (primavera-verão) a família se deslocava, de modo a beneficiar dos prazeres da vida no campo: o sossego, os convívios com amigos e convidados, com os quais se fruíam os banquetes, as caçadas ou os banhos nas termas. Em resumo, o otium que consolidava relaçôes de amizade ou de aliança político-económica. Desta vivência temos abundante documentação, desde a presença de ossos de gamo e veado em lixeiras de São Pedro (Fronteira), Torre de Palma (Monforte) e Quinta das Longas (Elvas) ${ }^{15}$, até às conchas de ostra frequentes nas villae do interior português, que mostram a ocorrência de banquetes de grande fausto, para os quais se construíram estruturas arquitetónicas cada vez mais monumentais e ricamente decoradas. Juntando os dois universos, a vida do campo com os prazeres da cidade, a villa é o elemento fundamental que domina os padrôes de povoamento. Embora geralmente se associe esta estrutura fundiária à região alentejana, dados os (errados) paralelos etnográficos com os montes e herdades, nos últimos anos a geografia das villae ampliou-se substancialmente, desde os territórios transmontanos (como o sítio de Rumansil, em Freixo de Numão) até às serranias da Beira Interior (como Prado Galego, em Pinhel), mostrando como a villa funcionou enquanto arquétipo civilizacional que se espalhou até aos limites da área sob domínio romano. Mostra também como, mesmo em regiões onde o tecido urbano era mais rarefeito, as villae se assumiam como locais de ostentação dos gostos cosmopolitas e como pontos de emanação dos valores ecuménicos para as comunidades envolventes, funcionando como marcos territoriais e elementos estruturantes da romanidade.

${ }^{15}$ Neste sítio identificaram-se ossos de perdiz-vermelha, certamente no âmbito de práticas de venatio (caçadas): ver Almeida e Carvalho 2005. 


\section{Os sítios: viver no campo na Lusitania}

Do ponto de vista estritamente numérico, a villa é o elemento que domina a paisagem romana, suplantando largamente outras unidades de povoamento. Todavia, defini-las em perspetiva conjunta é uma tarefa complexa, dada a tremenda diversidade de planos arquitetónicos e programas decorativos. Esta situação não é exclusiva da Lusitania, podendo afirmar-se que, por serem estruturas tão personalizadas ao gosto do proprietário (mesmo que um dominus detivesse várias ${ }^{16}$ ), não existem duas villae idênticas em todo o território do Império romano, quer no âmbito planimétrico, quer no programa decorativo.

Um elemento, contudo, é comum: a busca pelas paisagens ideais, conforme definido nos tratados de agricultura romanos. A estrutura construída procura a plena integração na paisagem, fundindo-se de modo harmónico na ordem cosmogónica que a envolve, constituindo-se como um espaço privilegiado para a fruição do panorama. Para tal, a estrutura deve implantar-se em pontos suficientemente elevados para que desfrute de amplos horizontes ${ }^{17}$, sem contudo se encontrar no topo, onde ficaria exposta aos ventos frios: o terço superior de uma encosta será o indicado ${ }^{18}$. Orientada a Sudoeste, para beneficiar da máxima exposição solar, deve dispor de abundantes aquíferos, sob a forma de mananciais ou de um ribeiro domesticado com um tanque ou barragem, formando um agradável espelho de água que, para mais, pode represar água útil para o edifício termal ou para a agricultura ${ }^{19}$. Por fim, na envolvente deve existir uma ampla variedade de classes de $\operatorname{solos}^{20}$, desde os solos pesados e férteis que propiciam culturas hortícolas de elevado rendimento, até extensas áreas apropriadas para olivais, ou o saltus que servia para atividades de caça (venatio), pastoreio ou recolha de lenha. Registe-se também que existe sempre uma distância prudente entre a villa e um troço viário principal: assim se compatibilizava o fácil e cómodo acesso para que o dominus chegasse da urbs onde residia, e o afastamento evitava os perigos e incómodos causados pelos viajantes em trânsito ${ }^{21}$.

${ }^{16}$ A título de exemplo, relembre-se o caso de Cícero: o grande tribuno chegou a deter nove villae em simultâneo, estando três delas na mesma província (a Campânia): Cumanum, Pompeianum e Puteolanum e, em cada uma, escreveu cartas e alguns discursos (Cic. de Orat. 2,9,10).

${ }^{17}$ A contemplação da paisagem envolvente provoca o desfrute da amoenitas envolvente. Para tal recorrem-se a várias soluções, como o banco corrido que acompanha a fachada oeste de Torre de Palma (Monforte), a varanda de São Cucufate (Vidigueira) ou os torreōes: quadrangular em villa Cardilium (Torres Novas) e octogonal em Cerro da Vila (Vilamoura).

${ }^{18}$ Col. R.r. 1,5; Varr. R.r. 1,12.

${ }^{19}$ Col. R.r. 1,5; Varr. R.r. 1,11.

${ }^{20}$ Palad. Opus Agr. 1,7; Varr., R.r. 1.12.

${ }^{21}$ Em média, as villae estão implantadas com distâncias de quinhentos metros a um quilómetro de um itinerário, beneficiando de um diverticulum, um caminho privado que muitas vezes ainda se nota na paisagem. Columela $(R . r .1,3 ; 1,5)$ e Varrão $(R . r .1,16)$ alertam para as perturbações da ordem e barulhos que os viajantes podem causar. 
O jogo harmonioso entre a paisagem envolvente e a estrutura construída prossegue no seu interior: através de artifícios por vezes espetaculares, procura-se que os elementos da Natureza sejam trazidos para o ambiente doméstico. Desde estuques pintados com paisagens até à utilização de jardins e fontes ou quedas de água em espaços concretos (por exemplo, o peristilo), procura-se uma imitatio da paisagem natural. Infelizmente, para a Lusitania estes ambientes são ainda mal conhecidos (por questões de conservação das estruturas), mas alguns casos existem, como o ninfeu na Quinta das Longas (Elvas), onde a água corria livremente pela sala, criando complexos jogos de luz no pavimento, ou as soluçôes em Santa Vitória do Ameixial (Estremoz), um sítio muito destruído, mas onde teriam existido cascatas em patamares, decorados com canteiros para plantas, acompanhando o desnível topográfico da elevação, criando assim pequenas cascatas ao longo das plataformas da residência.

A compreensão do que foram as villae da Lusitania está comprometida por uma deficiência de base: por enquanto, são poucas as villae escavadas na totalidade, o que não permite uma leitura satisfatória das planimetrias estruturais e dos espaços de vivência quotidiana. Mas pelos exemplos conhecidos, predomina o tipo de casa organizado em torno de um peristilo, um pátio colunado que pode ter um tanque ou jardim no centro, e que demonstra o modo como se impõem os protótipos helénicos na construção doméstica a partir do século I d.C.. A maioria das villae define um percurso axializado que parte do vestíbulo (sala de receção) para o peristilo e que encaminha o visitante para uma sala principal em abside ou tripla abside. Vários sítios fogem a esta tipificação, ou porque adotam outros planos (como a villa de São Cucufate, com o bloco de construções emoldurado por dois torreões laterais), ou porque não têm qualquer divisão que assuma a centralidade da casa, ficando esta com pequenas divisões, como no caso de Pisões (Beja), onde temos o átrio de tradição itálica. Esta diversidade "infinita" dos planos $^{22}$ com respeito pelos valores da simetria e equilíbrio clássicos, não inclui estruturas rurais que, pela dimensão, constituem verdadeiros palácios em meio rural, como as identificadas na Meseta espanhola, tendo em Carranque (Toledo) e Noheda (Cuenca) exemplos paradigmáticos. Todavia, a proximidade de La Cocosa (Badajoz) faz crer que nos campos portugueses existam exemplos semelhantes.

No interior, estes espaços apresentavam-se com uma rica e elaborada decoração que servia como referente comunicacional dos valores ecuménicos do dominus da propriedade. Os pavimentos de mosaicos mostram imagens que remetem para os valores da própria exploração, como as representações dos célebres "cavalos vencedores" de Torre de Palma (Monforte), ainda hoje implantada no centro de uma região de reconhecida tradição coudélica, mas note-se no mesmo local surgem requintadas representaçôes de cenas mitológicas ${ }^{23}$. Outros

${ }^{22}$ Gorges 1979115.

${ }^{23} \mathrm{O}$ nome atribuído a cada um dos cavalos remete para complexos panoramas mitológicos que evidenciam a grande carga cultural e conhecimento do dono da exploração e que se articulam 
mosaicos mostram valores de proveniências bem distantes, como a representação de Orfeu em Arnal (Leiria), evidenciando influxos culturais do Oriente, em paralelo aliás com o que se conhece para o território da Extremadura espanhola. A maioria dos elementos decorativos, contudo, perderam-se para sempre ou infelizmente chegaram até nós truncados. É o caso das esculturas, onde os escassos exemplos preservados dão uma pálida imagem da riqueza cénica dos ambientes onde estavam inseridas: o programa escultórico da Quinta das Longas (Elvas) decorava o ninfeu, onde a água circularia livremente, enquanto em Milreu (Faro) o conjunto de bustos de membros da casa imperial mostra como a família desta villa mantinha uma perceção estreita dos rostos que exerciam o poder em Roma. O quadro existente mostra como as villae da Lusitania tinham um aparato arquitetónico e decorativo que em nada ficava a perder para as outras províncias do Império. Mostram também como o conceito da villa enquanto local de fruição e de otium é levado ao limite, constituindo-se como células de urbanidade em meio rural.

Por contraponto, os outros sítios que compunham a paisagem rural da Lusitania não apresentam indícios de cosmopolitismo. Conhecemos poucos exemplos de aldeias, mas um caso interessante foi escavado em contexto de salvamento: em Monte da Nora (Elvas), encravado em pleno território das villae próximas da capital emeritense, temos uma aldeia que evolui em continuidade durante quase um milénio. Inicialmente um pequeno povoado indígena com sistemas defensivos (duas linhas de fossos com um portão central de acesso), que em momento imperial são condenados, em parte por estruturas de produção rústica (dois fornos cerâmicos, além de um lagar e dois tanques), reveladoras de um certo grau de auto-suficiência produtiva. O local é habitado até, pelo menos, ao século $\mathrm{V}$, altura em que se instala uma necrópole após o abandono dos espaços de vida ${ }^{24}$. Até então, os padrões cerâmicos mostram como a população de Monte da Nora (camponeses livres que geriam as suas terras? Ou que prestavam serviço nas villae em volta?) estava plenamente inserida nos circuitos de troca, dada a frequência de materiais de importação. Outros sítios revelaram moradias unifamiliares: nos últimos anos têm sido escavadas algumas, como em Terlamonte 1 (Covilhã) e Sardos (Monforte), onde junto à casa de habitação temos pequenos espaços produtivos com funções agro-pecuárias ou de fiação, e que mostram como pequenos casais agrícolas ocupavam as paisagens menos propícias para o estabelecimento de villae, albergando uma classe média rural que organizava o seu próprio sistema produtivo.

com a riqueza das cenas representadas em outros mosaicos (o triunfo báquico, as Musas, Apolo e Dafne, a luta de Teseu com o Minotauro, Hércules e Medeia). Desta forma temos um jogo de correspondências entre as temáticas eruditas de uma profunda mundividência e os emblemas da produção local, mostrando como estas elites fundiárias conseguiam criar um ornatus estético rico em valores e mensagens.

${ }^{24}$ Teichner 2008. 


\section{Os tempos: evolução e transformaçóes na paisagem romana da Lusitania}

A chegada e instalação de Roma trouxe um completo rasgar de horizontes no modo como cidade e campo eram vivenciados. Da geografia pré-existente pouco ficou, ou ficou apenas o que Roma quis, fosse por se encontrar em territórios periféricos, fosse por não apresentar interesse do ponto de vista da exploração económica. Deve, contudo, salientar-se (embora seja exterior ao âmbito temporal do presente texto) que a colonização romana foi antecedida por dois séculos de contatos comerciais e de presenças esporádicas com agentes da urbs latina e, anteriormente, com quase um milénio de trocas com diversas gentes do mundo mediterrânico, que foram criando novos modelos de organização social e económica em distintas regiōes da península.

O contributo de Roma para a criação de uma nova paisagem centra-se em dois universos: a escala, de um alcance inteiramente novo, pois a Lusitania integra-se agora nos circuitos de troca que vão das ilhas britânicas ao Próximo Oriente, assumindo uma grande centralidade nas rotas atlânticas; e uma nova estrutura territorial, assente em cidades e aglomerados urbanos que conectam com o mundo rural envolvente, criando uma aceleração nas dinâmicas quotidianas e nas relaçôes campo/cidade. Todavia, e no limite, o processo foi ainda mais radical, pois criou uma geografia humana com a fundação de cidades, a deslocação de gentes, a chegada de contingentes populacionais, os intercâmbios de ideias e as possibilidades de promoção social que trouxeram horizontes completamente novos às populaçôes deste território, estruturando um inédito "mapa cognitivo" à escala imperial ${ }^{25}$. De Salacia ${ }^{26}$ à Ammaia $^{27}$ vemos como as elites indígenas aproveitam as oportunidades, movimentando-se com grande à-vontade dentro dos padrões clássicos. Esta dinâmica é instituída em tempo de Júlio César, que fundou urbes situadas em pontos nevrálgicos, com a rede viária interligando estes pólos e colocando-os em interatividade com os campos envolventes e com outras cidades. Augusto aprofunda este processo, criando uma estratégia de pacificação e reconciliação, visível na denominação oficial das fundações urbanas, promovendo a colonização rural pela concessão de terras aos legionários, que serão os agentes privados de dinamização económica e os fundadores de uma sociedade provincial, através das alianças matrimoniais com as elites indígenas. Assim, com novas gentes, infra-estruturas, técnicas e produções, estabelece-se de modo gradual uma nova paisagem rural.

Os dados cerâmicos e os registos trazidos pelos naufrágios no Mediterrâneo mostram como a dinâmica económica em meio rural se implementa de modo rápido e seguro, podendo afirmar-se que no imperialato de Tibério já a Lusitania

\footnotetext{
${ }^{25}$ Nicolet 1996.

${ }^{26}$ Encarnação 1984 n ${ }^{\circ} 184 ; 185 ; 186 ; 187$.

${ }^{27}$ Encarnação 1984 nº 604; 615; 618
} 
se encontra plenamente integrada na geoestratégia romana. Também nos campos surgem, ainda na viragem da Era, as primeiras villae, com planimetrias de tipo itálico recorrendo aos módulos em torno de um átrio de entrada, mas já diferenciadas dos blocos compactos de inspiração militar designados (de modo pouco correto) como os castella do Sudoeste, ou das quintas republicanas sem núcleos distintivos identificadas na Andaluzia. O principal problema, para a investigação arqueológica, reside na dificuldade de leitura que alguns sítios apresentam, como se torna bem patente no exemplo de Castelo da Lousa (Mourão), que pela sua planimetria arquitetónica foi tendencialmente interpretado como de função militar, embora tenha tido uma vinculação à exploração agro-pecuária do território envolvente, como recentes reavaliaçōes deixam claro $^{28}$.

A existência das primeiras villae ainda está mal documentada do ponto de vista arqueológico, mas existem casos emblemáticos, como a designada "villa I” de Quinta das Longas (Elvas), cujas estruturas sobreviveram sob as paredes da "villa II" construída no século III, além de exemplos na envolvente de São Cucufate (Vidigueira) ${ }^{29}$. Este processo torna-se imparável ao longo dos séculos I e II d.C., com o alastramento das villae por todo o atual território português (a par do arroteamento de solos e da expansão da área cultivada), tendo tido uma inesperada vitalidade, com os sítios da Vidigueira a mostrarem um intenso ritmo de abandonos, reformulaçōes e transferências de proprietários, e iniciando-se assim o processo de concentração fundiária que reflete o reforço das elites. A senhorialização dos campos intensifica-se no século III, o momento em que se inicia a construção de villae áulicas e monumentais, emulando os protótipos das arquiteturas palatinas, como no exemplo de São Cucufate. Em alguns casos temos villae construídas de raiz, como em Quinta das Longas, onde a nova pars urbana se ergue sobre o que até então fora uma área produtiva, mas o fenómeno mais frequente é a progressiva ampliação das áreas construídas (o que talvez indique a persistência da propriedade na posse da mesma família), quer em extensão, como em Torre de Palma (Monforte), quer em altura, como em São Cucufate. Se alguns dos sítios evoluem dentro do quadro dos protótipos arquitetónicos convencionais, outros transferem para a região inesperados exemplos de originalidade e vanguardismo, como em Rabaçal (Penela), Horta da Torre (Fronteira) ou Abicada (Portimão), que mostram como as elites fundiárias estavam atentas à evolução dos morfotipos arquitetónicos e decorativos em experimentação no Império.

O momento de apogeu na monumentalização da paisagem rural da Lusitania ocorre no século IV, com a criação de espaços de representação da imagem e mundividência cultural do proprietário que apresentam grande ostentação e riqueza decorativa, como nas salas de receção, nos peristilos e nos edifícios termais. Entramos então na última fase de vivência nas villae, e em simultâneo,

\footnotetext{
${ }^{28}$ Alarcão, Carvalho, Gonçalves 2010.

${ }^{29}$ Mantas 1998; Mantas e Sillières 1990.
} 
a de maior esplendor: as estátuas, os ornamentos, os mosaicos, a profusa utilização de mármores e de estuques pintados, ou o recurso a jogos de água combinam-se em salas com imponentes abóbadas, vãos colunados e soluções arquitetónicas inesperadas, como os peristilos em sigma, as salas de tripla abside, os espaços hexagonais ou assimétricos, para criar ambientes sumptuosos e personalizados ao limite, de modo a que o dominus surja perante os seus convidados como alguém que emula os protótipos cerimoniais de ostentação que Constantino introduziu na corte imperial. As villae ganham por isso um protagonismo fundamental na paisagem, correspondendo à deslocação das sedes de poder do mundo público urbano em decadência para os pólos semi-privados, sejam as moradas urbanas (incluindo as da elite eclesiástica em ascensão) ou as residências no campo. A religião cristã toma um papel fundamental no processo, inicialmente incentivando a construção de espaços religiosos - basílicas e baptistérios - e em segunda fase, como detentora de terras que assume em gestão direta ou através dos bispos. Este é o último momento das villa $e^{30}$ : nos finais do século $\mathrm{V}$ e, sobretudo, ao longo do VI, o paradigma altera-se de modo decisivo. A religiáo cristã traz uma progressiva austeridade em favor de uma vivência despojada e humilde. A erudição literária pagã, onde os ornamentos visuais e decorativos ilustram as mitologias e referências greco-romanas, é substituída por uma vivência rigorista: as termas são fechadas e reaproveitadas como locais de culto ou de tumulação e as residências são habitadas de forma modesta ou abandonadas em definitivo. Na sociedade laica, o paradigma altera-se para uma apresentação mais militarizada, de acordo com as estéticas vigentes, por vezes trazidas por imigrantes e invasores das comunidades ditas bárbaras. Outros fenómenos ocorrem: o abandono de propriedades, anexadas por outras mais vastas, ocorrendo um processo de concentração fundiária do qual a própria Igreja participa. Por isso, a villa deixou de ser o ponto que simboliza o gosto urbano e a vivência do otium e da amoenitas: é agora uma unidade de produção agro-pecuária extensiva, ou foi abandonada e depois transformada em local de sepultamento, ou tornou-se a sede de um local de culto cristão que polariza as comunidades em volta. A gramática decorativa pagã, que demonstra a mundividência e cosmopolitismo do Império, apagou-se e foi substituída por uma estética rigorista, onde dominam os arquétipos próprios da linguagem cristã. A villa pólo de cultura é substituída por uma villa-basílica que na sua função de local de culto aglutina as comunidades que trabalham o campo do dominus ou do agente eclesiástico.

Ao longo do século VI as villae alteraram de modo radical o seu papel. A generalidade foi abandonada ao longo da centúria anterior, e as poucas que apresentam sinais de presença humana estão distantes do paradigma vivencial clássico: são zonas de atividade económica, transformadas em adegas, lagares ou armazéns (por vezes com silos ou talhas) sendo englobadas no domínio de

${ }^{30}$ Chavarría Arnau 2007. 
outras ou de agentes que vivem nas cidades. Temos uma reconfiguração da paisagem rural, com o incremento da base económica de sítios que anexam propriedades vizinhas e as transformam em espaços de laboração. A maioria foi abandonada, ficando apenas fenómenos de ocupaçôes pontuais, os designados squatters: lareiras, compartimentações de espaços áulicos, buracos de poste de cabanas para acolhimento de pessoas e animais. Abrigando-se entre ruínas, estas comunidades vão pilhar e espoliar os sítios faustosos ao abandono, retirando placas de mármore, esculturas e aparatos decorativos, procurando refúgios que deixam poucas evidências materiais: alguns fragmentos cerâmicos de pouca qualidade e restos de fauna, na maior parte das situaçôes, documentam uma realidade que só nos últimos anos foi identificada graças a escavaçôes mais rigorosas. Neste processo, contudo, duas situaçôes emergem com maior expressão material, ambas testemunhando a vivência cristã: por um lado, a utilização destes espaços como local de tumulação, testemunhando uma radical transformação no modo como as estruturas são entendidas, pois de espaço de vida convertem-se na última morada das comunidades ${ }^{31}$. As tumulações entre ruínas são bem conhecidas e espalham-se por toda a Lusitania, por regra no edifício termal, mas também em antigos templos ou na própria residência doméstica. Por outro lado, verifica-se a construção de espaços religiosos cristãos, que na fase inicial ocorre no interior da residência (como em Monte da Cegonha, Beja) para depois se transferir para as imediaçōes da pars urbana da villa, como em Torre de Palma (Monforte), neste caso sobre um anterior espaço de necrópole.

Esta diversidade de soluções no terreno ilustra uma tendência comum no espaço lusitano, que se manifesta de modo claro nos finais do século $\mathrm{V}$ e, de forma cada vez mais vincada, nas duas centúrias seguintes: a villa pode continuar a registar presença humana, mas de modo completamente diferente da sua raiz vivencial clássica. Existe uma reformulação completa de vivências, de significados e de conteúdos simbólicos nestas presenças, que nada têm a ver com aquilo que a villa significava na paisagem de época imperial. $\mathrm{O}$ modo como estes locais expressavam uma autoridade de cariz civil, cultural e político modificou-se para um plano religioso cristão, levando a que a perceção do espaço construído seja radicalmente distinta. Estas modificações ocorrem sem um padrão único, mas com cambiantes nos diferentes lugares, às vezes dentro da mesma área regional, mostrando como as generalizações são sempre tentadoramente perigosas. Neste aspeto, os séculos $\mathrm{V}$ e VI mostram no espaço lusitano o cruzamento de múltiplas influências, desde a marca cristã às presenças visigóticas e aos influxos culturais bizantinos, criando uma sociedade com distintos códigos e ambientes de vida e de morte. Os velhos campos da Lusitania são habitados de outras formas, continuando um processo de transformação que em breve irá conhecer outros atores: os colonizadores islâmicos.

${ }^{31}$ Este fenómeno parece ser bem delimitado no tempo, em torno aos fins do século IV e inícios do seguinte, pois nos momentos posteriores as necrópoles irão localizar-se junto dos edifícios de culto cristão que irão funcionar como elementos polarizadores das paisagens rurais. 


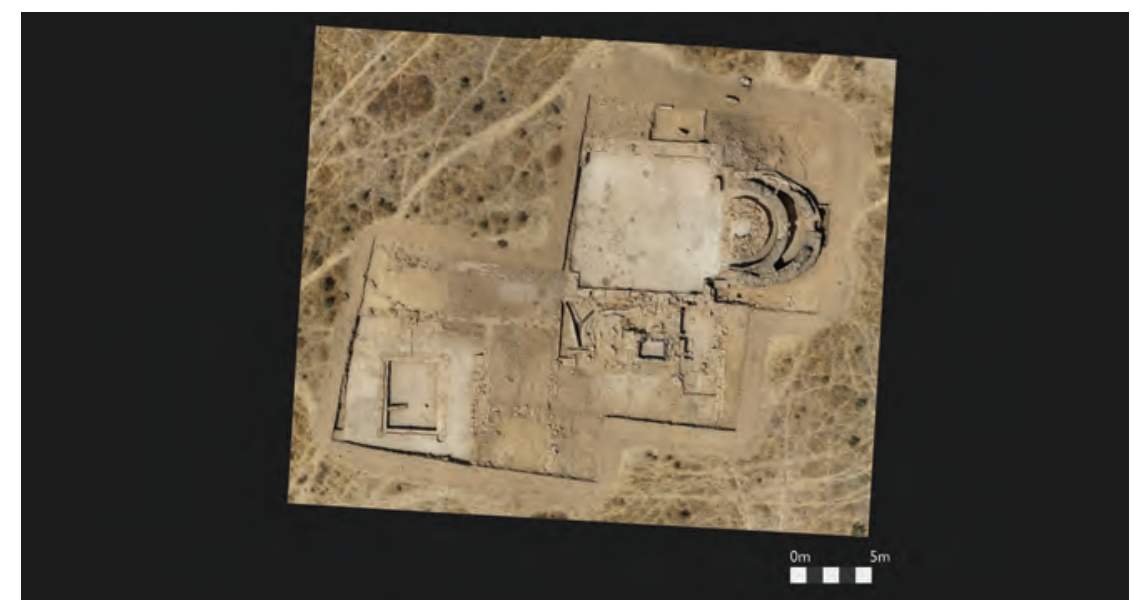

Fig. 1 - Villa romana da Horta da Torre no final dos trabalhos de 2017 (Fronteira) créditos: ortofotogrametria por Carlos Carpetudo, @Cromeleque

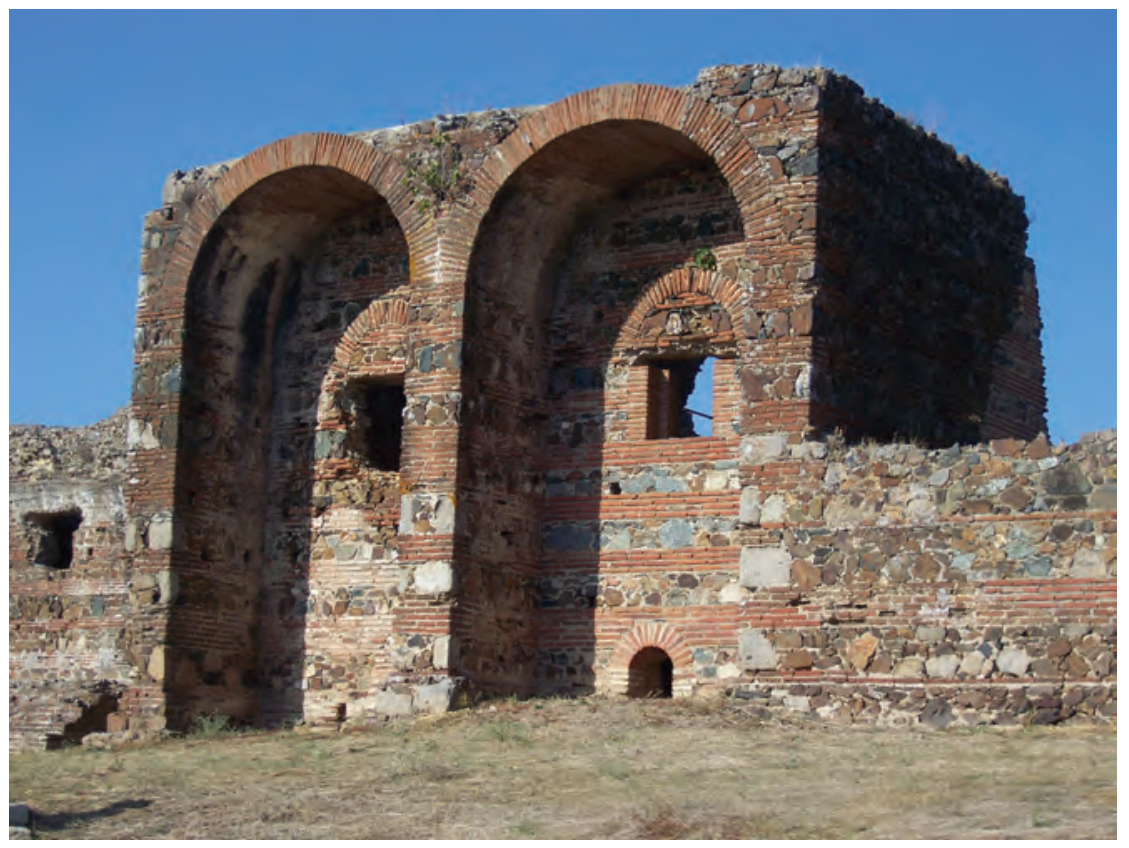

Fig. 2 - Villa romana de S. Cucufate (Vidigueira) - créditos do autor 


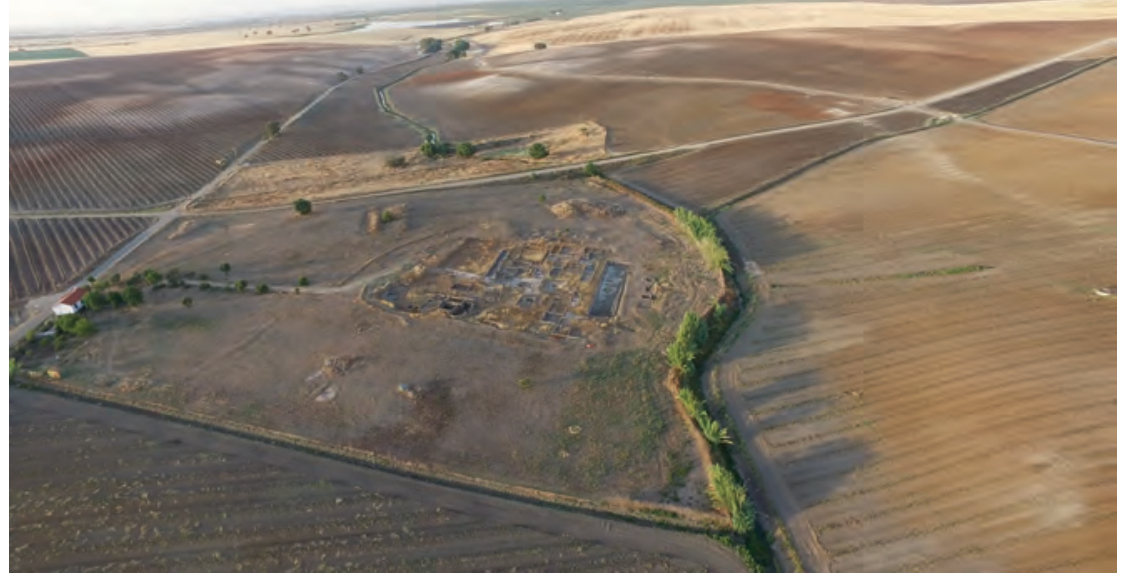

Fig. 3 - Villa romana de Pisóes - Imagem obtida por voo drone no decurso de projecto de levantamento ortofotogramétrico promovido pela Universidade de Évora (2017)

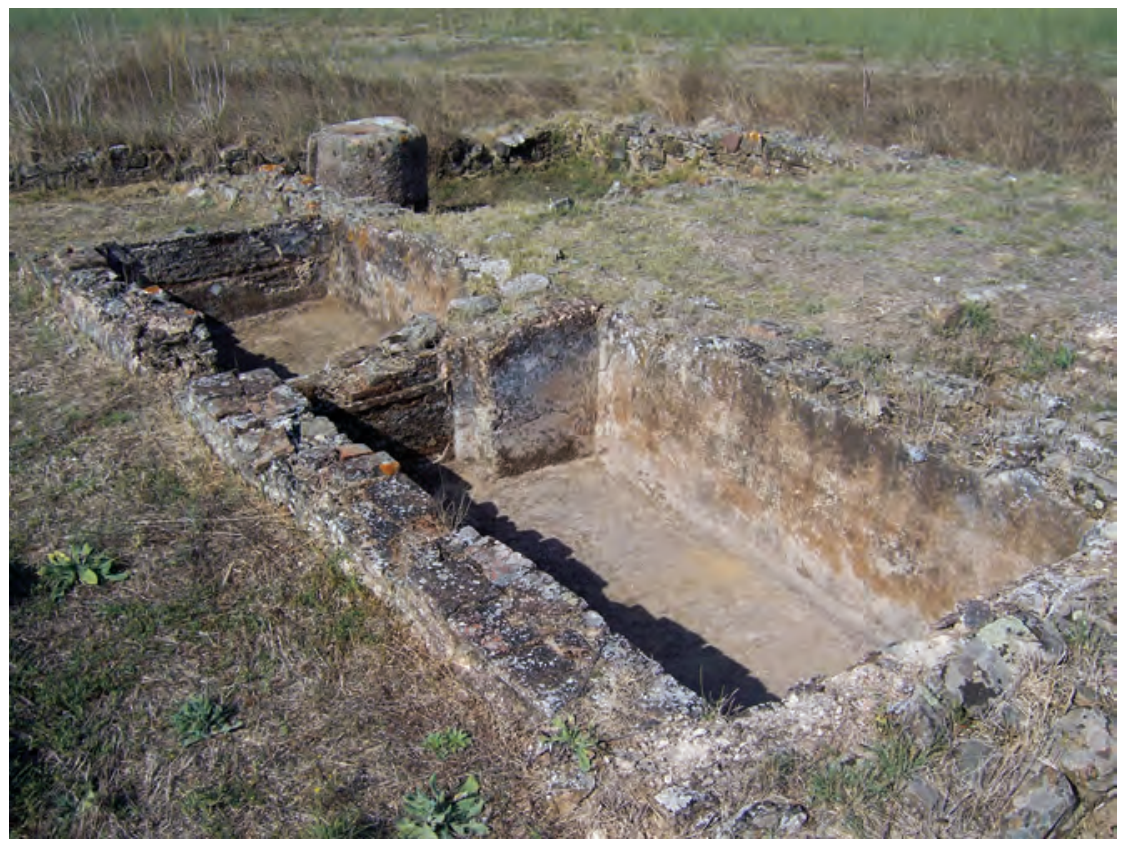

Fig. 4 - Villa romana de Torre de Palma (Monforte) - área de laboração do lagar. Créditos do Autor 


\section{Tábula cronológica}

[a partir de meados do século I a.C.] - Início da criação de uma paisagem rural romana, com evidências de uma sistemática produção agrícola

25 a.C. - Fundação de Augusta Emerita (Mérida), futura capital provincial da Lusitania, consolidando o processo de incremento da atividade agrí́cola

15/5 a.C. - Marcas de oleiro de terra sigillata itálica recolhidas em sítios próximos como Torre de Palma (Monforte) e Horta da Torre (Fronteira) sugerem que a construção de unidades de exploração agro-pecuária se encontra perfeitamente estabelecida.

[meados do século I d.C.] - Inversão da tendência: o registo anfórico mostra-nos como, de importadora, a Lusitania passa a exportar vinho e azeite

31 d.C. - Em Juromenha, o Pacto de hospitalidade coloca os clientes locais sob a proteção do legado imperial Lucius Fulcinius Trion. O tratado pode estar relacionado com a expedição de produtos agrícolas e cargas de mármore a partir daquele porto do Guadiana.

[meados do século III] - processo de reformulação na arquitectura das villae, que se irão tornar cada vez mais monumentais e elaboradas nos seus programas decorativos, iniciando uma exploração ainda mais intensiva do território.

[inícios do século IV] - primeiros indicadores da presença cristã nos campos, como no caso do compartimento 9 da villa da Quinta das Longas (Elvas). Durante esta centúria, assiste-se à construção de templos cristãos fora do edificado principal.

[Finais do século IV] - Início do processo de abandono ou reconversão das villae para outros fins.

407 - Início do processo de instalação de populações germânicas na Península Ibérica.

[século VI] - Fenómenos de ocupaçōes temporárias (squatters) e ocupaçōes em villae abandonadas coexistem com unidades em laboração sob controlo da Igreja.

\section{Bibliografia}

Alarcão, J. (1988), Roman Portugal. Londres, Warminster \& Phillips.

Alarcão, J. - Carvalho, P. C. - Gonçalves, A. (coord.) (2010), Castelo da Lousa - Intervençôes arqueológicas de 1997 a 2002. Mérida, MNAR (Studia Lusitana 5).

Alarcão, J. - Étienne, R. - Mayet, F. (1990), Les villas romaines de São Cucufate (Portugal). Paris, E. de Boccard.

Almagro-Gorbea, M. - Alvarez Martinez, J. M. (ed.) (1999), Hispania. El legado de Roma. Mérida, Museu Nacional de Arte Romano.

Almeida, M. J. - Carvalho, A. (2005), "Villa romana da Quinta das Longas (Elvas, Portugal): a lixeira baixo-imperial", Revista Portuguesa de Arqueologia 8 (1) 299-368.

Bernardes, J. P. (2007), A ocupação romana na regiāo de Leiria. Faro, Universidade do Algarve (Promontoria Monográfica 6).

Carneiro, A. (2014), Lugares, tempos e pessoas. Povoamento rural romano no Alto Alentejo. Coimbra (Humanitas Supplementum $\left.\mathrm{n}^{\circ} 30\right)$.

Carvalho, P. C. (2007), Cova da Beira. Ocupaçāo e exploração do território em época romana. Fundão/ Coimbra, Câmara Municipal do Fundão /IAFLUC (Conímbriga, Anexos 4).

Chavarria Arnau, A. (2007), El final de las villae en Hispania (siglos IV-VIII). Turnhout, Brepols Publishers (Bibliothéque de l'Antiquité Tardive 7).

Encarnação, J. d' (1984), Inscriçōes Romanas do Conuentus Pacencis. Coimbra, IAFLUC.

Fabião, C. (1993), "O passado proto-histórico e romano" in Mattoso, J. ed, História de Portugal, Vol. I. Lisboa, Editorial Estampa 79-299.

Gorges, J.-G. (1979), Les Villas Hispano-Romaines: inventaire et problématique archéologiques. Paris, E. de Boccard (Publications du Centre Pierre Paris, 4).

Lancha, J. - André, P. (2000), Corpus dos mosaicos romanos de Portugal. II - Conventvs Pacensis. 1 -A villa de Torre de Palma. Lisboa, Instituto Português de Museus, 2 volumes.

Lopes, M. C. (2003), A cidade romana de Beja. Percursos e debates acerca da "civitas" de Pax Iulia. Coimbra (Conimbriga Anexos 3). 
Mantas, V. (1986), "Implantação rural romana em torno da villa de S. Cucufate (Vidigueira)", Arquivo de Beja, 2a série, 3, 199-214.

Nicolet, C. ('1996), Linventaire du Monde. Géographie et politique aux origines de l'Empire romain. Paris, Hachette.

Peña Cervantes, Y. (2010), Torcularia. La producción de vino y aceite en Hispania. Tarragona, Institut Català d'Arqueología Clàsica (Documenta 14).

Quintela, A. - Cardoso, J. L. - Mascarenhas, J. M. (1987), Aproveitamentos Hidráulicos Romanos a Sul do Tejo: contribuição para a sua inventariação e caracterização. Lisboa, Ministério do Plano e da Administração do Território.

Santos, F. - Carvalho, P. C. (2008), "Aspectos do mundo funerário romano na Beira Interior. As estruturas monumentais da Quinta da Fórnea II (Belmonte)", Conímbriga 47 127-143.

Teichner, F. (2008), Entre tierra y mar. Zwischen Land und Meer. Architektur und Wirtschaftsweise ländlicher Siedlungsplätze im Süden der römischen Provinz Lusitanien (Portugal). Merida (Studia Lusitania 3). 
(Página deixada propositadamente em branco) 